\section{Proteins of the Cystic Fibrosis Respiratory Tract \\ Fragmented Immunoglobulin G Opsonic Antibody
Causing Defective Opsonophagocytosis}

Robert B. Fick, Jr., Gary P. Naegel, Susan U. Squier, Robert E. Wood, J. Bernard L. Gee, and Herbert $\mathbf{Y}$. Reynolds

Pulmonary Section, Department of Internal Medicine, Yale University School of Medicine, New Haven, Connecticut 06510; Department of Medicine, the University of Iowa, Iowa City, Iowa 52242; and the Department of Pediatrics, Case Western Reserve University Medical School, Cleveland, OH 44120 bstract. In the disease cystic fibrosis (CF), pulmonary infection with Pseudomonas aeruginosa is a common clinical complication that determines most morbidity and almost all excess mortality. We postulated that in this disease a defect in Pseudomonas-reactive IgG antibodies may contribute to chronic Pseudomonas infections.

Bronchoalveolar lavages were performed upon 13 patients with CF, 7 patients with chronic bronchitis characterized by recurrent Pseudomonas infections, and 4 normal volunteers. The levels of various proteins important to host defenses and proteases were determined; enzyme inhibition studies were performed. CF respiratory immunoglobulin levels were significantly elevated when compared with both normals and patients with chronic bronchitis $(P<0.05)$. Albumin and transferrin levels were decreased in the CF lung fluids. CF elastolytic activity

This work was presented in part at the American Society for Clinical Investigation meeting, 7-10 May 1982, and the American Thoracic Society national meeting, 15-18 May 1982, and has been published in abstract form in 1982, Clin. Res. 30:535 and 1982, Am. Rev. Respir. Dis. 125:193.

Address correspondence and reprint requests to Dr. Fick, Division of Pulmonary Diseases, The University of Iowa Hospitals and Clinics, Iowa City, lowa 52242. Dr. Fick is the recipient of Clinical Investigator Award no. HL-01065 from the National Heart, Lung and Blood Institute, an E. L. Trudeau Scholar Award of the American Lung Association, and during the performance of these experiments was the James Hudson Brown-Alexander B. Coxe Fellow at Yale School of Medicine.

Received for publication 12 October 1982 and in revised form 29 March 1984

J. Clin. Invest.

(c) The American Society for Clinical Investigation, Inc.

0021-9738/84/07/0236/13 $\$ 1.00$

Volume 74, July 1984, 236-248 was strikingly elevated $(\overline{\mathrm{x}}=6.02 \mu \mathrm{g} / \mathrm{mg}$ total protein) and the inhibitory profile suggested such activity resembled a serine-proteinase. Alpha-1-antitrypsin antigenic levels were not altered in CF respiratory fluids. There was a tendency for the lavage IgG to fall as elastase levels rose $(r=-0.29)$.

IgG opsonins for two Pseudomonas immunotypes were isolated with affinity chromatography for functional and immunochemical studies. Bacterial phagocytic rates in the presence of these Pseudomonas-reactive IgG opsonins derived from $\mathrm{CF}$ lavage fluid were depressed $(0.3 \%$ uptake/unit time) when compared with similarly titered positive controls (uptake $=1.3 \%$ unit time, $P<0.001$ ). Additionally, normal pulmonary macrophage intracellular killing of Pseudomonas was severely altered in the presence of opsonins derived from CF respiratory fluids. At some time points, $<30 \%$ of the bacteria were killed. CF IgG opsonins contain a cleavage fragment $(100,000$ $D$, 5S sedimentation coefficient) with antigenic determinants similar to the Fab portion of IgG. The presence of such a fragment was inversely correlated with phagocytic functional activity. Intact IgG comprised as little as $18 \%$ of the CF lavage fluid specimens. Aliquots of intact human IgG, when mixed with the CF opsonins, augmented Pseudomonas uptake and improved intracellular killing. Conversely, peptide fragments of IgG opsonins, which are proteolytically derived in vitro, duplicated in our system the defect observed with opsonins derived from CF lung fluids; bacterial uptake was inversely related to the concentration of $F\left(a b^{\prime}\right)_{2}$ and to a greater degree, to Fc present in the opsonic mixture. We conclude that IgG respiratory opsonins are fragmented, inhibiting phagocytosis and serving a permissive role in the chronic Pseudomonas pulmonary infection in the disease CF. 


\section{Introduction}

Whole sera from homozygous cystic fibrosis $(\mathrm{CF})^{1}$ patients have been shown to inhibit the ability of rabbit and human pulmonary macrophages (PM) to ingest and destroy Pseudomonas aeruginosa (Pseudomonas) (1-3). Biggar et al. (3) concluded that CF serum was deficient in a phagocytic factor, probably IgA, and Thomassen and co-workers (1) have characterized this factor as a heat stable protein. Additionally, the existence of bactericidal blocking antibodies have been proposed to explain the selective inability of CF whole serum to support Pseudomonas bactericidal activity (4). In a preliminary publication, Bell and Spock (5) have suggested that dimeric secretory IgA within CF respiratory secretions blocks the bactericidal activity of IgG.

Recently, we isolated IgG antibodies reactive with Pseudomonas surface lipopolysaccharide (LPS) from the serum of CF subjects (6) and studied the ability of these opsonins to promote phagocytosis and intracellular killing of $P$. aeruginosa in an in vitro human PM culture system. We discovered that circulating IgG antibodies in CF were inhibitory to both the uptake and intracellular killing of these bacteria (7). Assessing the functional activities of the Fab and Fc portions of the IgG antibody molecules revealed an impairment in the attachment, via the Fc portion, of these LPS-reactive antibodies to the PM membrane $\mathrm{Fc}_{\gamma}$ receptors. Preliminary studies of the physicalchemical properties of these serum immunoglobulins were normal (7).

Optimal phagocytosis of Pseudomonas requires the presence of heat-stable opsonins $(8,9)$ and of the heat-stable opsonins; IgG has superior protective activity when compared with IgA or IgM (10). In part, this is explained by the presence of immunoglobulin receptors of the $\mathrm{Fc}_{\gamma}$ class on the surface membranes of macrophages obtained from normal human volunteers (11). Moreover, it is known that papain- or pepsin-digested IgG lacks opsonic activity (12), and that free Fc fragments inhibit rosetting and erythrophagocytosis of erythrocytes coated with immunoglobulins of like IgG subclasses (13). Our work had suggested that a defect in the Fc portion of CF-derived antiPseudomonas IgG interfered with macrophage phagocyte function by preventing proper receptor attachment and subsequent internalization of opsonized bacteria.

In this most common of all lethal genetic diseases, persistent pulmonary infection is the single most important clinical complication determining host morbidity and almost all mortality

1. Abbreviations used in this paper: $\alpha-1-\mathrm{AT}$, alpha-1-antitrypsin; BAL, bronchial-alveolar lavage; $C$, complement; $\mathrm{CB}$, chronic bronchitis; $\mathrm{CF}$, cystic fibrosis; $\mathrm{CFU}$, colony forming units; HA, hemagglutination; HIS, serum derived from a pool of normal individuals hyperimmunized with the heptavalent Pseudomonas vaccine; IVIgG, intact IgG prepared for intravenous administration; LPS, lipopolysaccharide; PAG, polyacrylamide gel; PM, pulmonary macrophages; PMST, phenylmethylsulfonylfluoride; $R_{f}$, mobility; SC, free secretory pieces of IgA; SLAPN, succinylL-alanyl-L-alanyl-L-alanine-p-nitroanilide; STI, soybean trypsin inhibitor, Tris- $\mathrm{HCl}$, hydroxy-methyl-aminomethane buffer solution.
(14). The key to improving survival is the early institution of an effective therapy before these patients have suffered irreversible lung damage. We postulate in the present studies that a defect in Pseudomonas IgG antibodies present within the CF respiratory tract serves as a permissive factor which fosters chronic Pseudomonas infection.

\section{Methods}

Experimental specimens and bronchial-alveolar lavage $(B A L)$. Therapeutic bronchial washings were performed upon thirteen patients with CF (9 male, 4 female) with a mean age of 17 yr \pm 1.4 SD (range: 9-27 yr). All had, predominantly, chronic Pseudomonas colonization of their sputum and moderate or severe obstructive airways disease. New alveolar filling patterns on chest roentgenographs, indicative of an active pneumonitis, were not present. The CF patients had never smoked tobacco. BALs were performed for diagnostic reasons on seven patients with fixed, moderate, or severe obstructive airways disease, daily copious sputum production characteristic of chronic bronchitis (CB), and clinical courses punctuated by chronic ( $>6 \mathrm{mo}$ ) respiratory infections with Pseudomonas. Three of these patients were male and four were female, mean age was $59 \mathrm{yr} \pm 5.4 \mathrm{SD}$, and all seven subjects had smoking histories. Additional lavages were performed upon four normal subjects (three male, one female) with a mean age of $29 \mathrm{yr} \pm 3.5$; two were smokers. These normal controls had no history of previous Pseudomonas infections and had not recently experienced a respiratory infection. Blood was previously obtained from normal individuals who were actively immunized (HIS) with a heptavalent Pseudomonas lipopolysaccharide vaccine (Warner-Lambert/Parke-Davis, Detroit, MI) as a part of an earlier study (15). Serum was separated, pooled, and stored at $-35^{\circ} \mathrm{C}$. To obtain an IgG-enriched globulin fraction, serum was processed as described previously (7).

Lung lavage to obtain respiratory secretions from $\mathrm{CB}$ and control subjects was performed and the fluids were processed as previously reported $(16,17)$. CF bronchopulmonary lavage was performed by positioning a $4.5-\mathrm{mm}$ (inside diameter) cuffed endotracheal tube into a lobar or main stem bronchus, using a 3,5-mm flexible bronchoscope to guide the tube into place. The location of the tube was confirmed visually, the bronchoscope withdrawn, and the cuff inflated. The lung distal to the cuff was then lavaged with 3-7 liters of isotonic saline in aliquots of $100-300 \mathrm{ml}$. The first liter of effluent collected for use in this study was centrifuged to sediment the respiratory cells. Supernate of the lavage fluid was decanted, total protein levels were determined as discussed below, and the fluid concentrated $10-25$-fold at $4^{\circ} \mathrm{C}$ using positive pressure ultrafiltration (Amicon Corp., Scientific Systems Div., Danvers, MA). The concentrated BAL was then dialyzed against $0.02 \mathrm{M}$ Tris$\mathrm{HCl}$ (hydroxymethyl-aminomethane), $\mathrm{pH} 7.6$, in preparation for isolation of total IgG and prior to various protein determinations. Cells obtained from normal volunteers were processed for short-term tissue culture and employed in the phagocytic and bactericidal assays as previously described (7).

Protein determinations. Total protein was determined by the method of Lowry et al. (18) at two stages in the handling of the lavage fluids: immediately after decanting from the airway cells, and again after positive pressure concentration and dialysis. BAL concentrations of albumin, IgG, IgA, IgM, IgE, complement (C) 3c, transferrin, and $\alpha$-1-antitrypsin $(\alpha-1-\mathrm{AT})$ were determined by radial immunodiffusion (Tri-Partigen and LC-Partigen radioimmunodiffusion plates, Calbiochem-Behring Corp., American Hoechst Corp., San Diego, CA). Radial immunodiffusion 
methods permitted the detection of as little as $50 \mu \mathrm{g} / \mathrm{ml}$ of antigenic $\alpha-1-A T$ in lung lavage fluid. Precipitate intensification with tannic acid was unnecessary. Lung lavage proteins were then expressed as percent of BAL total protein.

Elastase levels were determined in the $\mathrm{CF}, \mathrm{CB}$, and normal volunteer lavage fluids, and the cell lysates of normal human $\mathrm{PM}$ and polymorphonuclear (PMN) leukocytes. Protease was obtained from a CF clinical isolate of Pseudomonas aeruginosa by the methods of Higerd et al. (19). Elastolytic activity was measured by slight modification of two methods previously employed (20). First, insoluble elastin prepared from nuchal ligament elastin (Sigma Chemical Corp., St. Louis, MO) was labeled with ${ }^{14} \mathrm{C}$-methyl groups (21) and used as a substrate. Standards of porcine pancreatic elastase at 60 units $/ \mathrm{mg}$ (Sigma Chemical Co.) were routinely included for comparison. Approximately $5 \mathrm{ng}$ of pancreatic elastase could be detected with this substrate. A second method employed the artificial elastin substrate, succinyl-L-alanyl-L-alanyl-L-alanine-p-nitroanilide ("SLAPN", Bachem, Torrance, CA), as a substrate (22). Hydrolysis of SLAPN was measured spectrophotometrically using an 18$\mathrm{h}$ incubation with $10 \mu \mathrm{l}$ of BAL fluids or cell lysates at $37^{\circ} \mathrm{C}$ in Tris$\mathrm{HCl}$ buffer and measuring the change in absorbance at $410 \mathrm{~nm}$. The sensitivity of this assay is such that $2 \mathrm{ng}$ of porcine pancreatic elastase can be detected.

Proteinase inhibition. Pulmonary macrophage, PMN leukocyte, and Pseudomonas elastases have been isolated previously and differ in their inhibition profiles (23-25). Therefore, it was possible to differentiate PM and Pseudomonas elastases (largely metallo-proteinases) from PMN elastase (serine proteinase) in BAL fluid. Soybean trypsin inhibitor (STI), phenylmethylsulfonylfluoride (PMSF) (Sigma Chemical Co.), and ethylene diamine tetraacetic acid (EDTA) were used in elastase inhibition studies. For this, BAL samples were preincubated at $37^{\circ} \mathrm{C}$ for $30 \mathrm{~min}$ with one of these inhibitors before one of the elastase substrates, SLAPN and ${ }^{14} \mathrm{C}$-elastin, was added. The assay was then performed as described previously (20). As an additional control, the solvent for PMSF, isopropyl alcohol, was incubated alone with the substrates prior to measuring elastolytic activity. The inhibitor studies were expressed as percent of control activity.

Isolation of IgG reactive with Pseudomonas surface LPS. An IgGenriched globulin fraction was derived from pooled HIS specimens as described $(7,26)$. The concentrated respiratory secretions were mixed with diethylaminoethyl cellulose gel as an initial step at $4^{\circ} \mathrm{C}$ (Microgranular DE52, Whatman Laboratory Products, Clifton, NJ), the eluent was filtered by gravity, and the ion-exchange gel was washed with a 0.2 $\mathrm{M} \mathrm{NaCl}$ solution (6). The BAL fractions were then processed as were the serum specimens, i.e., column chromatography with Sephadex G-200 or occasionally Sepharose 6B (Pharmacia Fine Chemicals, Piscataway, $\mathrm{NJ}$ ), and the purified IgG within the elution fractions identified by double immunodiffusion precipitation. An affinity gel was devised as previously reported (6) with types 4 and 6 specific Pseudomonas LPS coupled to CNBr-activated Sepharose 4B (Pharmacia Fine Chemicals). The HIS and BAL IgG-rich fractions were passed through this immunoadsorbent twice. Passive hemagglutination titers were determined against all seven Pseudomonas serotypes as previously reported $(6,7)$.

Pseudomonas phagocytic assay. Lavage fluids obtained from four normal healthy adult volunteers were centrifuged to sediment the respiratory cells. Supernatant fluid was decanted and stored at $-70^{\circ} \mathrm{C}$ for protein determinations and isolated of IgG at a later time. The respiratory cell pellet was then processed in a standard fashion for short-term in vitro cell cultures $(6,9,10,16,17,20)$. The cells were resuspended in serum-free McCoy's 5A medium (Gibco Laboratories, Grand Island, $\mathrm{NY}$ ) to a concentration of $5 \times\left(10^{5}\right)$ viable cells $/ \mathrm{ml}$, and $1 \mathrm{ml}$ was placed into $2.0 \mathrm{~cm}^{2}$ plastic tissue culture chambers (Nunclon Delta Multidishes, Vangard International, Neptune, NJ) and incubated $16 \mathrm{~h}$. In the performance of a single bacterial uptake and bactericidal experiment in which the cells were obtained from a single normal subject, we simultaneously tested in duplicate the function of three or four CF BALderived IgG opsonins, as well as a positive and a negative control.

Clinical isolates of $P$. aeruginosa were serotyped and a stock culture was prepared as previously discussed (7). Immunotype 4 organisms, which were originally mucoid strains, were obtained from a CF sputum specimen, and the immunotype 6 Pseudomonads were cultured from the blood of a patient with a necrotizing pneumonia. Before each phagocytic assay, a vial of type 4 or type 6 reference Pseudomonas was thawed and inoculated into a mixture of tryptic soybroth (Pfizer Diagnostics Division, Pfizer Inc., New York) and $0.05 \mathrm{mCi}{ }^{14} \mathrm{C}$-L-amino acid mixture (New England Nuclear, Boston, MA) and incubated overnight. The radiolabeled bacteria were then washed repeatedly and resuspended in sterile saline to a concentration of $5\left(10^{7}\right)-5\left(10^{8}\right)$ colony forming units (CFU)/ml by directly counting a diluent in a darkfield Petroff-Hausser chamber (Neubauer pattern bacterial counting chamber, American Scientific Products, McGaw Park, IL). Concentrations were confirmed by quantitative pour plates.

Pseudomonas IgG agglutinins derived by affinity chromatography from HIS and lavage specimens were used as sources of opsonic antibodies. For opsonization prior to the phagocytic assay, these agglutinins were adjusted to equal titers of LPS type 4 or 6 hemagglutination (HA) activity or equivalent milligram per milliliter $\mathrm{IgG}$ protein concentrations when derived from negative (normal volunteer) controls. Washed suspensions of ${ }^{14} \mathrm{C}$-labeled reference Pseudomonas organisms $\left(10^{7}-10^{8} / \mathrm{ml}\right)$ were added to the Pseudomonas LPS-reactive IgG antibodies and incubated at $37^{\circ} \mathrm{C}$ for $30-60 \mathrm{~min}$. The bacteria were then centrifuged, resuspended in saline to a concentration of $1\left(10^{7}-10^{8}\right) / \mathrm{ml}$, and in 10 $100 \mu$ aliquots (Pseudomonas:PM ratio, 10:1), dispensed into the macrophage monolayers.

At predetermined intervals, duplicate monolayers were randomly selected, the supernatant fluids decanted, and the cell layers repeatedly washed. The PM cell layers were disrupted by the addition of $1 \mathrm{ml}$ of distilled water, scraped with a rubber policeman 30 min later, and a $100 \mu \mathrm{l}$ aliquot of this lysate was used to determine bactericidal rates as detailed below. Phagocytic rates were determined as previously reported (7). Briefly, cell lysates were transferred to scintillation vials, mixed with a premixed scintillation solution, and counted for ${ }^{14} \mathrm{C}$-activity in a liquid scintillation spectrometer (LS-100C, Beckman Instruments Inc., Fullerton, CA) by counting twice for $10 \mathrm{~min}$. The net counts were expressed as mean counts per minute, and the bacterial uptake was expressed as percent of the original bacterial inoculum ${ }^{14} \mathrm{C}$-counts that remained with the washed and lysed PM monolayer.

Bactericidal assay. At various times after the opsonized bacterial challenge and incubation, the monolayers were lysed with distilled water, and $100 \mu \mathrm{l}$ were serially diluted in sterile saline and inoculated into liquid tryptic soy agar plates. After incubation for $36 \mathrm{~h}$, these quantitative pour plates were examined under a darkfield colony counter (American Optical, Scientific Instruments Division, Buffalo, NY) and the number of CFU electronically recorded. Throughout the assay, representative $100 \mu \mathrm{l}$ samples of the original Pseudomonas inoculum were counted similarly to assure that the bacteria remained in lag phase growth. The percent of intracellular bacteria that were no longer viable was expressed for each opsonic source at each time point as follows: Number of intracellular bacteria $=$ percent uptake $\times$ CFU in original inoculum; Percent killed bacteria $=$ (total uptake number - viable CFU in monolayer lysate/number of intracellular bacteria) $\times 100 \%$. 
Fc and $F\left(a b^{\prime}\right)_{2}$ inhibition studies. The hypothesis that free $\mathrm{Fc}$ and $\mathrm{F}\left(\mathrm{ab}^{\prime}\right)_{2}$ fragments are capable of inhibiting uptake of $P$. aeruginos $a$ by PMs was tested by: $(a)$ generating these functionally important peptides from IgG antibodies by conventional means, and $(b)$ adding these fragments, in increasing concentrations, to intact IgG opsonins employed in the phagocytic assay described above. An IgG-enriched fraction with significant HA activity for Pseudomonas immunotype 4 (1:256) was generated from pooled human serum using previously described methods $(7,26)$. This IgG antibody preparation consisted entirely of intact IgG as determined by polyacrylamide gel electrophoresis and double immunodiffusion analyses. Such IgG antibodies were then subjected to standard hydrolytic proteolysis by papain (27) and pepsin (28). The Fc and $F\left(a b^{\prime}\right)_{2}$ fragments were recovered from the papain and pepsin digests, respectively, by means of affinity chromatography on a column of Protein A-Sepharose CL 4B (Sigma Chemical Co.). Elution was performed in a stepwise manner with $0.15 \mathrm{M}$ buffered saline of increasing acidity: pH 8.6, 7.0, 5.5, 4.3, and 2.3 (29). Fractions were screened by Oüchterlony analysis for antigenic reactivity with monospecific antisera to human $\mathrm{IgG} \mathrm{Fc}$ fragment and human IgG Fab fragment. Molecular weights of the purified antigenic fragments were determined by polyacrylamide gel (PAG) electrophoresis (see "Immunochemical determinations"). Affinity-purified specimens were pooled, dialysed against PBS, pH 7.0, and concentrated by positive pressure filtration (Amicon Corp.). Protein concentration was assessed by the method of Lowry et al. (18).

A washed solution of radiotagged $P$. aeruginosa immunotype 4 was inoculated into a tumbled PM solution (Pseudomonas:PM ratio of 1:1) containing $200 \mu \mathrm{g}$ of intact IgG antibodies with reactivity to Pseudomonas surface LPS Fisher type 4. Increasing amounts of $F c$ or $F\left(a b^{\prime}\right)_{2}$ fragments were added to the opsonic mixture resulting in final peptide:IgG ratios ranging from $0.1: 1$ to $5: 1$; each particular ratio of $F c$ or $F\left(a b^{\prime}\right)_{2}$ to $\operatorname{IgG}$ was run in duplicate. After $60 \mathrm{~min}$ of tumbling and incubation at $37^{\circ} \mathrm{C}$, phagocytosis was halted with cold $\mathrm{NaF}$ washes after the method of Murphey et al. (30). Bacterial uptake was determined by counting cell lysates in a scintillation counter as described above.

IgG-potentiated phagocytosis and bacterial killing. A preparation of intact IgG for intravenous administration (IVIgG) was kindly provided by Dr. J. A. Hooper (Hyland Therapeutics Division, Travenol Laboratories, Inc., Glendale, CA). This preparation was reconstituted with $50 \mathrm{ml}$ sterile pyrogen-free water; Pseudomonas LPS HA titers were determined; and $2-\mathrm{ml}$ aliquots were stored at $-70^{\circ} \mathrm{C}$ for use in the phagocytic and bactericidal assays. IVIgG opsonins were incubated with radiotagged Pseudomonads, and employed in the bacterial uptake and killing assays as described above, generating dose-response curves. Mixing experiments were performed with four of the CF BAL-derived affinity purified IgG opsonins as follows: Bacteria were incubated in the presence of a mixture of the opsonins derived from CF lung fluids and equivalent HA titers of IVIgG. These opsonized bacteria were washed and then inoculated into the PM monolayers and handled as discussed earlier. Augmented phagocytic and bactericidal rates were compared with rates generated by use of the same CF opsonins alone, which were assayed simultaneously. The optimal effective replacement ratio of IVIgG expressed: IVIgG (milligrams)/CF IgG (milligrams) was computed by holding constant the milligram amount of CF IgG used, varying the amount of IVIgG employed during opsonization, and performing the phagocytic assay noting optimal uptake.

Immunochemical determinations. Double immunodiffusion precipitation tests were performed with Noble agar (Difco Laboratories, Inc., Detroit, MI) in borate saline (31). IgG fractions of rabbit antisera specific for human IgG, $\mathrm{Fc}_{\gamma}$, Fab, and gamma-heavy and light chain portions were obtained from Behring Diagnostics (Calbiochem-Behring Corp.).
We performed micro-immunoelectrophoresis using $1.2 \%$ agar ("lowion," Difco Laboratories, Inc.) in $0.03 \mathrm{M}$ barbital buffer, pH 8.1, by a modification of the method of Wieme (32).

Sucrose density. Lavage fluid IgG-enriched fractions and the Pseudomonas LPS-reactive IgG fractions eluted from affinity columns were layered on $10-40 \%$ linear sucrose density gradients and subjected to ultracentrifugation at $37,000 \mathrm{rpm}$ at $4^{\circ} \mathrm{C}$ for $18 \mathrm{~h}$ (L5-50 ultracentrifuge, Beckman Instruments Inc.). Normal human IgG (7S) and albumin (5S) were labeled with ${ }^{125} I$ by the methods of Fraker and Speck (33) and served as sedimentation markers. The fraction volumes from each gradient were comparable. Portions of each gradient were dialysed against distilled water and submitted for polyacrylamide gel electrophoresis. Relative concentrations of $\mathrm{IgG}$ antigenic subunits $\left(\mathrm{Fc}_{\gamma}, \mathrm{Fab}\right)$ were determined with specific antisera and double immunodiffusion precipitation analysis.

Polyacrylamide gel electrophoresis. Vertical slab electrophoresis was performed using a Bio-Rad Laboratories electrophoresis cell with standard $17.8 \times 14-\mathrm{cm}$ glass plates and $1.5-\mathrm{mm}$ spacers. A $10.0 \mathrm{~cm}$ lower separating gel with a $10.0 \%$ polyacrylamide concentration, in a $0.1 \%$ sodium dodecyl sulfate (SDS), $0.375 \mathrm{M}$ Tris- $\mathrm{HCl}, \mathrm{pH} 8.8$, buffer and a $1.0 \mathrm{~cm}$ upper stacking gel with a $3.0 \%$ polyacrylamide concentration in $0.1 \%$ SDS, $0.125 \mathrm{M}$ Tris- $\mathrm{HCl}$, $\mathrm{pH} 6.8$, was routinely used (34). A running buffer made of $0.025 \mathrm{M}$ Tris- $\mathrm{HCl}, 0.19 \mathrm{M}$ glycine, and $0.1 \%$ SDS was used (35). Equal volumes of sample containing 60-100 $\mu \mathrm{g}$ protein and sample buffer consisting of $0.25 \mathrm{M}$ Tris- $\mathrm{HCl}, \mathrm{pH} 6.8,4.0 \% \mathrm{SDS}, 20 \%$ glycine, and $0.002 \%$ bromophenol blue were mixed and placed in a boiling water bath for $1 \mathrm{~min}$. Electrophoresis was performed at $25 \mathrm{~V}$ constant voltage for $17 \mathrm{~h}$ and then increased to $100 \mathrm{~V}$ for $2 \mathrm{~h}$ to bring the bromophenol blue leading front within $1 \mathrm{~cm}$ from the bottom of the gel. Gels were stained overnight in $0.04 \%$ Coomassie Brilliant Blue. Electrophoretic mobilities were calculated by the methods of Weber and Osborn (36): Mobility $\left(\boldsymbol{R}_{\mathrm{f}}\right)=($ protein migration/gel length after staining $) \times($ gel length before stain/dye migration)

Gel transfer and autoradiography. BAL IgG fractions in triplicate were first subjected to electrophoresis in one dimensional SDS-PAG as detailed above. The proteins were then transferred to nitrocellulose sheets by modification of the method of Towbin et al. (37). A sheet of nitrocellulose with a $0.45-\mu \mathrm{m}$ pore size was cut from a roll (Millipore Corp. Bedford, MA), wetted with transfer buffer ( $25 \mathrm{mM}$ Tris, $0.19 \mathrm{mM}$ glycine in $20 \% \mathrm{vol} / \mathrm{vol}$ methanol, $\mathrm{pH} 8.3$ ), and laid on a Scotch Brite pad (3M Corp., Minneapolis, MN) supported by a plastic grid. The SDS-PAG to be transferred, another scouring pad, and plastic support were bound to the nitrocellulose sheet by elastic bands. Positions of the protein columns were noted on the sheets. The gel-nitrocellulose assembly was then placed into a Plexiglass transfer assembly with the nitrocellulose sheet facing the anode, the transfer buffer filled the chambers, and electrophoresis proceeded at $35 \mathrm{~V}$ for $105 \mathrm{~min}$. After fixing, the gel was stained in $0.2 \%$ Coomassie Blue.

Specificity of the electrophoretic bands was determined with scintillation autoradiography. The nitrocellulose sheets were rinsed in Burridge's buffer $(0.9 \% \mathrm{NaCl}: 10 \mathrm{mM}$ Tris- $\mathrm{HCl}, \mathrm{pH} 7.4)$ and soaked in Burridge's buffer with $3 \%$ bovine serum albumin (BSA, Sigma Chemical Co.) at $37^{\circ} \mathrm{C}$ for $2 \mathrm{~h}$ and room temperature for $90 \mathrm{~min}$. The sheets were vigorously washed in Burridge's buffer $\times 5$ and soaked overnight in this rinse buffer. The nitrocellulose sheets were then cut with a razor blade to separate individual IgG electrophoresis columns run in triplicate. These sections of the nitrocellulose paper were placed into plastic trays $(20 \times 30 \mathrm{~cm}$ with $5-\mathrm{cm}$ wide slots) and each was covered with rabbit antisera specific for $\mathrm{Fc}_{\gamma}$, Fab, or light-chain portions of human IgG diluted 1:40 in 3\% BSA-Burridge's buffer. Nitrocellulose sections and 
antisera were reacted at room temperature for $2 \mathrm{~h}$ and then once again vigorously washed as above. Staphylococcal protein A was labeled with ${ }^{125} \mathrm{I}(7)$, and at an activity of $5-10\left(10^{5}\right) \mathrm{cpm} / \mathrm{ml}$ was used to counterstain the nitrocellulose sheets. After additional vigorous washings, the sheets were air-dried and exposed to Gevaert double emulsion film at $-70^{\circ} \mathrm{C}$ for 2-6 h. The film was developed in a standard x-ray developer (Eastman Kodak, Rochester, NY).

Statistical analysis. Protein levels were analyzed by computer utilizing SAS and Datatext programs for Student's $t$ tests, nonparametric Wilcoxon (rank-sum) tests, and Pearson's correlation coefficients. Arithmetic means, standard deviations, and standard errors of the mean of the phagocytic and bactericidal data were analyzed by both Student's $t$ tests for paired data ( $P$ values are for a two-tailed test). Slopes were calculated from the mean curves by using the methods of least squares and linear regression analysis. $r$ values are Pearson's correlation coefficients obtained from a correlation matrix.

\section{Results}

Protein levels in bronchoalveolar lavage fluids. The CF BAL fluid return was generally $>50 \%$ with a mean of $67 \% \pm 10$ (SD), and no significant differences in the percent return were found when compared with normals, those with $\mathrm{CB}$, or smokers compared with nonsmokers. The method developed for BAL of those with CF was well tolerated.

The mean levels of seven proteins important in the defense of the respiratory membrane were quantitated in BAL fluids from normal volunteers and those with $\mathrm{CF}$ and $\mathrm{CB}$ troubled by recurrent Pseudomonas infections (Table I). CF respiratory immunoglobulin levels, except the IgM value, were significantly elevated when compared with normals. In particular, antigenic IgG levels determined by radial immunodiffusion were strikingly elevated. Albumin when expressed as percent of total lavage fluid protein was unexpectedly decreased in those secretions obtained from patients with CF. Similarly, the derived values for unconcentrated CF lavage fluid albumin and transferrin were significantly decreased $(P<0.05)$ when compared with normal values.

Proteases, antiproteases, and inhibition profiles. Lavage fluid elastolytic activities, determined with both SLAPN and insoluble elastin substrates and expressed per milligram of total protein, are summarized in Table II. This activity, irrespective of the method of measurement, was significantly elevated when compared with that of normal volunteer respiratory secretions. Because the respiratory tracts of both $\mathrm{CF}$ and $\mathrm{CB}$ subjects present several possible sources for such a protease, we tried to localize elastolytic activity to the most probable source, i.e. human alveolar macrophages, circulating PMN leukocytes, as well as $P$. aeruginosa. All three of these contained proteolytic activity similar to the porcine pancreatic elastase standard, although the levels varied depending upon the density of the cell or bacterial suspension: $10^{7}$ PMN leukocytes when disrupted contained 2.0$20 \mu \mathrm{g}$ elastolytic activity; $10^{7} \mathrm{PM}=0.7-6 \mu \mathrm{g}$; Pseudomonas, both mucoid and nonmucoid strains, resuspended to a concentration $10^{9} / \mathrm{ml}$ contained $3.0-45 \mu \mathrm{g} / \mathrm{ml}$.

To further characterize BAL elastase activities found with either substrate, we performed three experiments (Table II). Based on the differential inhibitory effects of EDTA, PMSF, and STI together, the data indicate that elastase in the CF BAL has features of a serine proteinase in contrast with normal lavage fluid elastase which was largely inhibited by EDTA. Respiratory fluids obtained from patients with $\mathrm{CB}$ and chronically colonized with Pseudomonas yielded contradictory results, in that elastolytic activity was inhibited by STI but not PMSF as was expected. As has been reported by others, we discovered that both Pseudomonas and PM-associated protease activities were largely metalloproteases (both 87-100\% EDTA-inhibitable), and that the circulating PMN leukocyte elastolytic activity was inhibited by PMSF and STI, thereby identifying it as a serine proteinase.

$\alpha-1-\mathrm{AT}$ is the major naturally occurring antielastase present within the normal respiratory tract. We measured antigenic levels in all three sources of respiratory fluids. Low but reproducible levels were measured in normals $(\bar{X}=27 \mu \mathrm{g} / \mathrm{mg}$ total protein). There were no significant differences in the values obtained from CF (30 $\mu \mathrm{g} / \mathrm{mg})$ or CB (18 $\mu \mathrm{g} / \mathrm{mg})$ subjects when compared with the low normal values.

$C F$ protein correlations. Several interesting correlations resulted from a detailed statistical analysis of the seven $C F$ lavage

Table I. Lavage Proteins* in BAL Fluids from Normals and Subjects with CF and CB

\begin{tabular}{|c|c|c|c|c|c|c|c|c|}
\hline & $\begin{array}{l}\text { Total } \\
\text { protein }\end{array}$ & Albumin & $\operatorname{IgG}$ & IgA & IgM & IgE§ & $\mathrm{C} 3 \mathrm{c}$ & Transferrin \\
\hline Normal $(n=4)$ & 1.30 & $\begin{array}{c}0.52 \\
(40) \ddagger\end{array}$ & $\begin{array}{r}0.07 \\
(5.6)\end{array}$ & $\begin{array}{c}0.03 \\
(2.6)\end{array}$ & $\begin{array}{r}0.006 \\
(0.48)\end{array}$ & $\begin{array}{c}0.004 \\
(0.27)\end{array}$ & $\begin{array}{l}0.013 \\
(1.0)\end{array}$ & $\begin{array}{c}0.08 \\
(6.3)\end{array}$ \\
\hline $\mathrm{CF}(n=13)$ & 1.25 & $\begin{array}{l}0.25 \\
(20)^{\prime \prime}\end{array}$ & $\begin{array}{c}0.34 \\
(27.0)^{\prime \prime}\end{array}$ & $\begin{array}{c}0.07 \\
(5.4)^{\prime \prime}\end{array}$ & $\begin{array}{r}0.004 \\
(0.35)\end{array}$ & $\begin{array}{c}0.015 \\
(1.18)^{\prime \prime}\end{array}$ & $\begin{array}{c}0.03 \\
(2.1)^{\prime \prime}\end{array}$ & $\begin{array}{c}0.03 \\
(2.7)^{\prime \prime}\end{array}$ \\
\hline $\mathrm{CB}(n=7)$ & 5.14 & $\begin{array}{c}0.77 \\
(15)^{\prime \prime}\end{array}$ & $\begin{array}{c}0.24 \\
(4.6)\end{array}$ & $\begin{array}{r}0.07 \\
(1.5)\end{array}$ & $\begin{array}{r}0.007 \\
(0.14)\end{array}$ & - & - & - \\
\hline
\end{tabular}

* Milligrams or units/milliliter unconcentrated BAL. ‡ Mean values expressed as percentage of total protein are given in parentheses. § Units/ milligram of total protein. " $P<0.05$ compared with normal. I Inadequate no. of samples. 
Table II. Lung Lavage Elastases* and Inhibition Profiles $\ddagger$

\begin{tabular}{lccc}
\hline & Normal (7) & CF (13) & CB (4) \\
\hline Elastase $\left({ }^{14}\right.$ C-Elastin) & 0.10 & $6.02 \S$ & $2.28 \S$ \\
With EDTA & 87 & 13 & 7 \\
With PMSF & 29 & 77 & 33 \\
With STI & 10 & 84 & 68 \\
Elastase (SLAPN) & 0.02 & $1.85 \S$ & $3.45 \S$ \\
With EDTA & 100 & 0 & 0 \\
With PMSF & 26 & 63 & 0 \\
With STI & 31 & 99 & 61
\end{tabular}

* Mean levels expressed as $\mu \mathrm{g} / \mathrm{mg}$ lavage total protein. $\ddagger$ Expressed as percent inhibition of control elastolytic activity. $\S P<0.05$, compared with normal.

fluid proteins. ${ }^{2}$ Pseudomonas LPS HA titers quantified in the CF BAL correlated in a positive fashion with the elevated antigenic IgG levels $(r=0.99, P=0.001)$. There was a tendency for the same BAL IgG $(r=-0.29)$ and Pseudomonas titers $(r$ $=-0.40$ ) to fall as elastase levels rose, although not in a statistically significant fashion. Elastolytic activity was positively correlated $(r=0.76, P=0.04)$ with the age in years of $C F$ patients.

Phagocytic functions of CF IgG opsonins derived from respiratory fluids. When IgG fractions prepared from HIS and various lung lavage fluids were passed through a specific LPS affinity gel, antibodies eluted with augmented HA titers to a single Pseudomonas immunotype. In practice, the affinity gel, whether immunotype 4 or 6 , functioned equally well when presented with IgG enriched from serum or lavage fluid provided that the ratio of IgG (milligrams) to affinity gel matrix (milliliters) was $>1.0$. HA titers of the postaffinity antisera samples, as expected, correlated in a step-wise fashion with the milligram per milliliter protein (IgG) concentrations (shown for immunotype 4 in Fig. 1).

The type 4 and 6 reference organisms, originally mucoid clinical isolates, incorporated the ${ }^{14} \mathrm{C}$-label avidly. After several saline washes $>98 \%$ of the remaining radioactivity was associated with the Pseudomonads. The organisms grew vigorously while incubated in tryptic soy broth, but converted to a lag phase growth pattern when in saline solutions, distilled water, or at room temperature over the course of the phagocytic and bactericidal assays.

Uptake of type $4 P$. aeruginosa was studied using IgG opsonins derived from CF respiratory fluids ( $n=14$ experiments), CB lavages $(n=4)$, HIS used as a positive control $(n=10)$, and normal volunteers' lavage fluids $(n=9)$ used as negative controls. Radiotagged Pseudomonas microorganisms were taken up by normal PM, irrespective of the source of the opsonin, in

2. Pseudomonas LPS HA titers in CF BAL also correlated significantly $(P<0.005)$ with albumin, IgE, C3c, C4, and $\alpha-1-\mathrm{AT}$ levels.

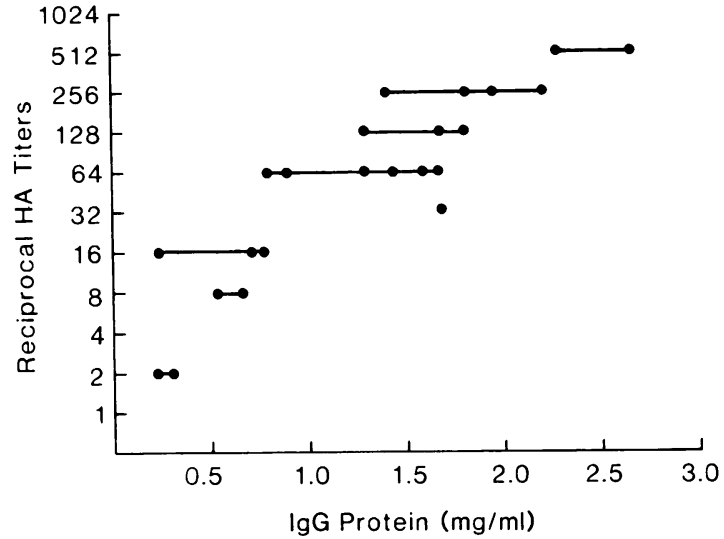

Figure 1. Postaffinity column IgG HA titers to Pseudomonas type 4 surface antigen. Reciprocal HA titers to Pseudomonas immunotype 4 (ordinate) plotted for protein levels of these IgG antibodies (abscissa). The immunotype 4 agglutination titers rise in a stepwise fashion as the IgG levels increase.

a linear fashion $(r>0.90)$ when studied over the first $60 \mathrm{~min}$ (38). Despite the equivalent $\mathrm{HA}$ titers, the $\mathrm{CF}$ phagocytic rate $(0.3 \% /$ unit time) was significantly depressed when compared with the HIS rate $(1.3 \% /$ unit time, $P<0.001$ at $60 \mathrm{~min})$. The absolute uptake of bacteria in the presence of the CF BAL IgG opsonins was also less than the HIS at each time point $(P$ $<0.05$ ). Substituting an immunotype 6 strain of $P$. aeruginosa and CF IgG eluted from a gel matrix prepared with type 6 LPS immunoadsorbents resulted in bacterial uptakes that did not significantly differ from the phagocytosis of immunotype 4 facilitated by CF antibodies: uptake type 4 at $60 \mathrm{~min}=12 \%$; uptake type $6=12 \%$; uptake type 4 at $120 \mathrm{~min}=16 \%$; uptake type $6=19 \%, P>0.01$. Even though the CF respiratory antibodies contained appreciable Pseudomonas LPS-hemagglutinating titers, the initial rate and absolute uptakes did not differ in any respect from the control IgG without agglutinating activity but used in equivalent milligram amounts. Pseudomonas reactive IgG antibodies obtained from a small number of selected CB sources achieved levels of bacterial uptakes that were greater than negative and $C F$ sources at two time points ( 30 and 120 min, $P<0.01$ ); yet, the initial rate of phagocytosis was not significantly improved.

We previously had performed extensive scanning electron microscopic experiments to demonstrate that with this particular assay most of these cell-associated organisms were in fact intracellular and not simply aggregated on PM surface membranes (7). Routine washing of these monolayers removes some surface adherent, noningested bacteria and leaves $2-6 \%$ of the monolayer ${ }^{14} \mathrm{C} \mathrm{cpm}$ extracellular and not internalized. Such an error, which is inherent in our technique, will nullify the statistical significance reached at $2 \mathrm{~min}$. The significance of other CF- and HIS-mediated bacterial phagocytic kinetics remain unaltered and the same relationships persist. 
Bactericidal function of $C F$ opsonic antibody. During the phagocytic experiments, aliquots of duplicate PM monolayer lysates were serially diluted, cultured, and then viable bacteria were enumerated. CFU of bacteria obtained on duplicate specimens approximated each other closely. Table III presents the mean percent of internalized type 4 bacteria that were killed by the normal human PM. By computing the percent bacteria killed for only those Pseudomonads internalized by PM (CF uptake $=8-18 \%$ of original inoculum), it was possible to study the effectiveness of intracellular bactericidal mechanisms alone. The HIS IgG opsonins $(n=8)$ were associated with $>98 \%$ killing after $15 \mathrm{~min}$ incubation, which emphasizes that pulmonary macrophages when properly primed are very potent bactericidal phagocytes. The negative control IgG immunoglobulins, despite supporting a meager phagocytic rate, resulted in $70 \%$ killing of internalized bacteria after $2 \mathrm{~h}$. In this respect, CF respiratory opsonins functioned poorly, since killing of Pseudomonas was significantly inhibited when compared with both positive (HIS) and negative controls (Table III). At some time points, 15-60 min, $<30 \%$ of the internalized bacteria were killed when the CF opsonins were present.

Immunochemical properties of $C F$ and $C B$ respiratory opsonins. Pseudomonas IgG antibodies, isolated from $\mathrm{CF}$ respiratory fluids and eluted from LPS affinity gels, were identified with antisera ( $\mathrm{Fc}_{\gamma}$, Fab specificity), by double immunoprecipitation techniques. Purified IgG antibody from HIS, normal volunteers, and specimens obtained from those with $\mathrm{CB}$ yielded single precipitin bands when the antiserum specific for Fab antigenic portion of IgG was employed. However, five of the seven CF IgG antibody preparations consistently resulted in two concentric immunodiffusion arcs when rabbit anti-human IgG (Fab) antiserum was employed. When $\mathrm{Fc}_{\gamma}$ antiserum was used to qualitatively identify the CF IgG fractions, only a single precipitin arc resulted. Further analysis of the Pseudomonas LPS-reactive IgG opsonins immunoelectrophoretically gave similar information (Fig. 2). The cathodal migration of IgG immunoglobulins derived from normal serum and normal BAL resulted in single immunoprecipitin arcs with $\mathrm{Fc}_{\gamma}$ and $\mathrm{Fab}$ antisera, respectively. CF IgG antibodies reactive with immunotype 4 Pseudomonas

Table III. CF Respiratory IgG Opsonins Mean Bactericidal Function*

\begin{tabular}{|c|c|c|c|c|c|c|c|c|}
\hline \multirow[b]{2}{*}{$\begin{array}{l}\text { Opsonin } \\
\text { source }\end{array}$} & \multirow[b]{2}{*}{ (No.) } & \multicolumn{7}{|c|}{ Minutes after inoculation } \\
\hline & & 2 & 15 & 30 & 60 & 120 & 180 & 240 \\
\hline HIS & (8) & $94 \ddagger$ & 97 & $>98$ & $>98$ & $>98$ & $>98$ & $>98$ \\
\hline Negative & (5) & 68 & 67 & 53 & 44 & 73 & 71 & 70 \\
\hline $\mathrm{CF}$ & (7) & 47 & 25 & 28 & 21 & 43 & 54 & 70 \\
\hline COPD & (4) & 92 & 71 & 95 & 88 & 88 & 96 & 92 \\
\hline
\end{tabular}

COPD, chronic obstructive pulmonary disease.

* Corrected for uptake.

$\ddagger$ Percent killed $=[($ Percent uptake $\times$ inoculum CFU $)-$ PM lysate CFU/ uptake number] $\times 100 \%$.

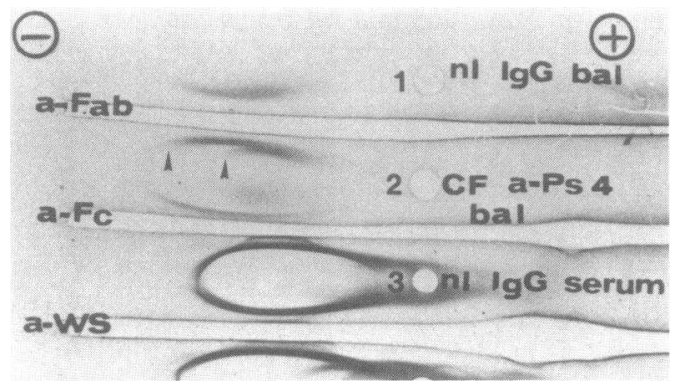

Figure 2. CF IgG opsonin immunoelectrophoretic pattern developed with antisera specific for the Fab (a-Fab) and the Fc (a-Fc) regions of IgG, and antisera against whole serum (a-WS). Normally, the electroosmosis of IgG results in a single cathodal precipitin arc when the IgG has been isolated from lavage fluids (IgG BAL) or serum (IgG serum) and eluted from a Pseudomonas LPS affinity gel (wells 1 and 3 , respectively). However, CF BAL processed in an identical fashion (CF bal a-Ps 4) resulted in two faint intersecting immunoprecipitin arcs (arrows). Each arc contained IgG Fab antigenic reactivity. a-Ps 4, anti-Pseudomonas immunotype 4.

antigen contained an additional component resulting in atypical bowing and a long tail. This added protein contained antigenic reactivity similar to IgG $\mathrm{Fab}$ portions but not to $\mathrm{Fc}_{\gamma}$.

Confirmatory, nonimmunoelectrophoretic data pertaining to the size or intactness of IgG antibody from CF BAL specimens were sought using sucrose density gradients (Fig. 3). The radioactivity of the ${ }^{125} \mathrm{I}-7 \mathrm{~S}$ marker of purified human IgG coincided with the position of IgG antibody derived from CF serum and from normal serum or lavage fluids in gradient fractions. However, the Pseudomonas-reactive IgG molecules obtained from CF lung lavages were present in multiple later fractions of the gradient. These smaller subunits of IgG had a sedimentation coefficient similar to a radiotagged human serum albumin marker (4.6S). Again, such a 5S component of IgG was present in five of seven CF samples and not in the CB specimens (two examined).

Gel electrophoresis, transfers, and autoradiography. To analyze further protein components of the IgG opsonins obtained from the CF respiratory tract, electrophoresis on SDS-PAG was used. Molecular weight standards, calculation of mobility constants, and integration of the protein bands from a single specimen proved to be of value. As illustrated in Fig. 4, IgG obtained from the lung lavage fluid of a normal subject without Pseudomonas-agglutinating activity (column 5) was largely (86\%) composed of a single protein band with a mobility constant $\left(R_{f}\right)$ of 0.57 in this system and a molecular weight of $158 \mathrm{kD}$. CF lavage fluid IgG (denoted as total CF BAL IgG) prior to affinity chromatography (columns 6-9) yielded multiple protein bands with mobility constants of $0.57-0.84$, corresponding to molecular weights from $158 \mathrm{kD}$ to $25 \mathrm{kD}$. The intact IgG protein $(158 \mathrm{kD})$ comprised as little as $18 \%$ of these preparations and no more than $62 \%$ (Fig. 4). After affinity chromatography, the CF respiratory opsonins (columns 2-4) were largely (78-100\%) composed of a fragment of IgG with a mobility of 0.70 and a 


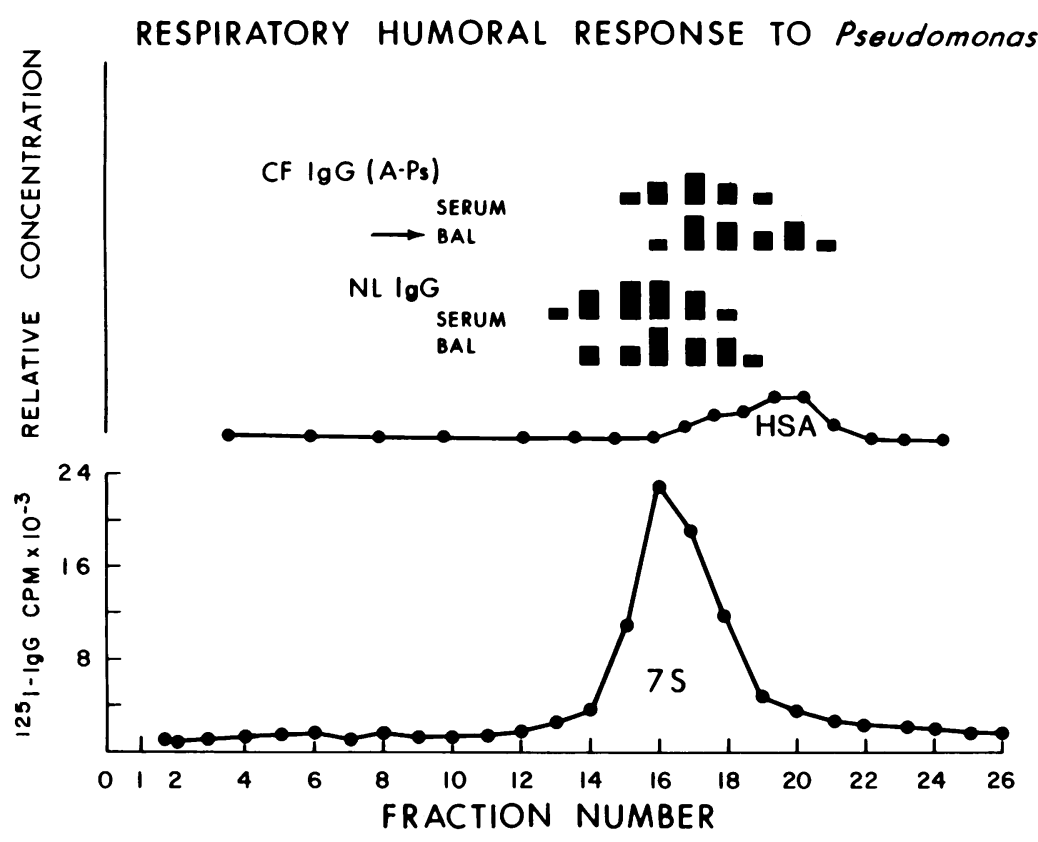

Figure 3. Determination of sedimentation coefficients. A representative sucrose density gradient experiment shows simultaneously separated ${ }^{125}$ I-labeled normal serum IgG (lower ordinate), and serum and BAL IgG from both CF and normal volunteer sources. The relative concentrations of the immunoglobulins are denoted by bar graphs (upper ordinate) for each gradient fraction (abscissa) in which IgG appears. The Pseudomonas-reactive portion of CF respiratory $\mathrm{IgG}$ resulted in two peaks: $7 \mathrm{~S}$ and a smaller fragment with a sedimentation coefficient of $5 \mathrm{~S}$ similar to that of human serum albumin (HSA) identified, here, by double immunodiffusion analysis.

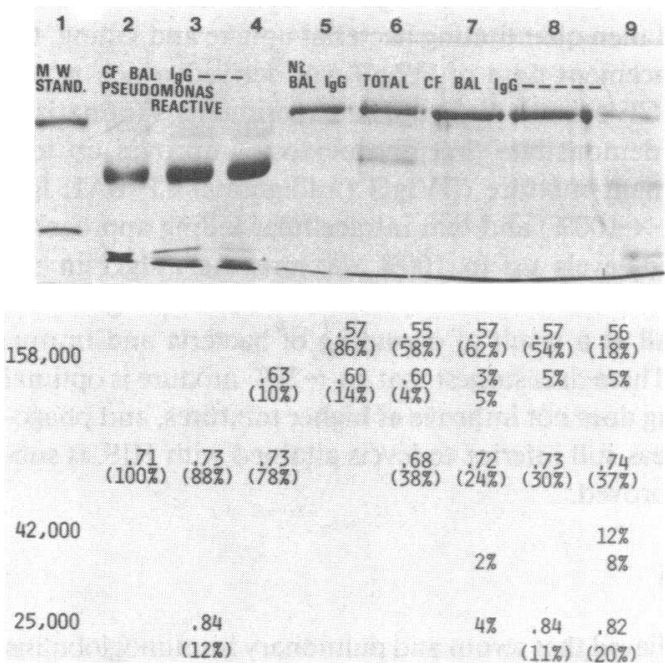

Figure 4. Electrophoresis of CF respiratory opsonins in $0.1 \%$ SDS, $10 \%$ PAG. The numbers in the lower portion of the figure correspond to the individual protein bands (above) stained with Coomassie Brilliant Blue. Mobility $\left(R_{f}\right)$ is given as a fraction and was calculated: $\boldsymbol{R}_{\mathrm{f}}=$ (protein migration/gel length prior to stain) $\times$ (gel length after stain/bromophenol migration). The percent of total sample protein that the individual band represents is derived from a scanner with auto-integration and is given in parentheses. Molecular weight standards (M. W. Stand.; column 1) which include aldolase (158 kD), ovalbumin (45 kD), and bromophenol blue indicate the leading front. Normal lavage fluid IgG (column 5) was composed of a single protein band ( $158 \mathrm{kD}, R_{\mathrm{f}}=0.57$ ) while total CF BAL IgG (6-9) yielded multiple bands ( $\left.25-158 \mathrm{kD} ; R_{f}=0.57-0.84\right)$. The CF opsonic IgG molecules derived from affinity gels $(2-4)$ were largely a single protein fragment $\left(100 \mathrm{kD}, R_{\mathrm{f}}=0.70\right)$. molecular weight of $\sim 100 \mathrm{kD}$. In parallel experiments, IgG, derived from the BAL fluids of four CB patients, was electrophoresed on similar 10\% PAG and studied densitometrically resulting in $36-84 \%$ of the total protein as an intact $158 \mathrm{kD}$ band (not shown); up to $30 \%$ of the CB protein fragments migrated as a $50,000-60,000-k D$ protein with mobility constants of $0.78-0.81$.

With electrophoretic transfer of CF SDS-PAG proteins to nitrocellulose sheets, and then staining with antisera specific for antigenic portions of IgG and counterstaining with a radiolabel, the immunochemical identification of IgG fragments was possible (Fig. 5). No loss of resolution of the original SDS-PAG band pattern (to the left of each pair) was noted, although the transfer was not quantitative. The lower molecular weight protein fragments produced more distinct autoradiographs. Total CF respiratory IgG was composed of multiple cleavage fragments with mobilities and molecular weights as defined above and antigenic identity with $\mathrm{Fab}, \mathrm{Fc}_{\gamma}$, and $\kappa$ - or $\lambda$-light chain subunits (Fig. 5). Three bands contained antigenic reactivity similar to Fab derived from IgG (column 2), and a single SDS-PAG protein band seemed to represent free $k$-light chains (column 6 ). The ${ }^{125}$ I-tagged $\mathrm{Fc}_{\gamma}$ antisera (column 4) labeled two bands: one of higher molecular weight $(158,000 \mathrm{D})$ and one of $\sim 40,000 \mathrm{D}$.

The functional importance of these $100-\mathrm{kD} 5 \mathrm{~S}$ fragments was assessed further. As mentioned in two of the seven $\mathrm{CF}$ opsonic preparations, such an IgG cleavage product could not be identified with our methods. The individual bacterial uptakes $\left({ }^{14} \mathrm{C} \mathrm{cpm}\right.$ [\%], Fig. 6, upper portion) and the bactericidal data (CFU [\%], Fig. 6, lower section) potentiated by CF opsonins were plotted in a scatter diagram and the presence or absence of such a $5 \mathrm{~S}$ component was noted. Those IgG opsonins in 


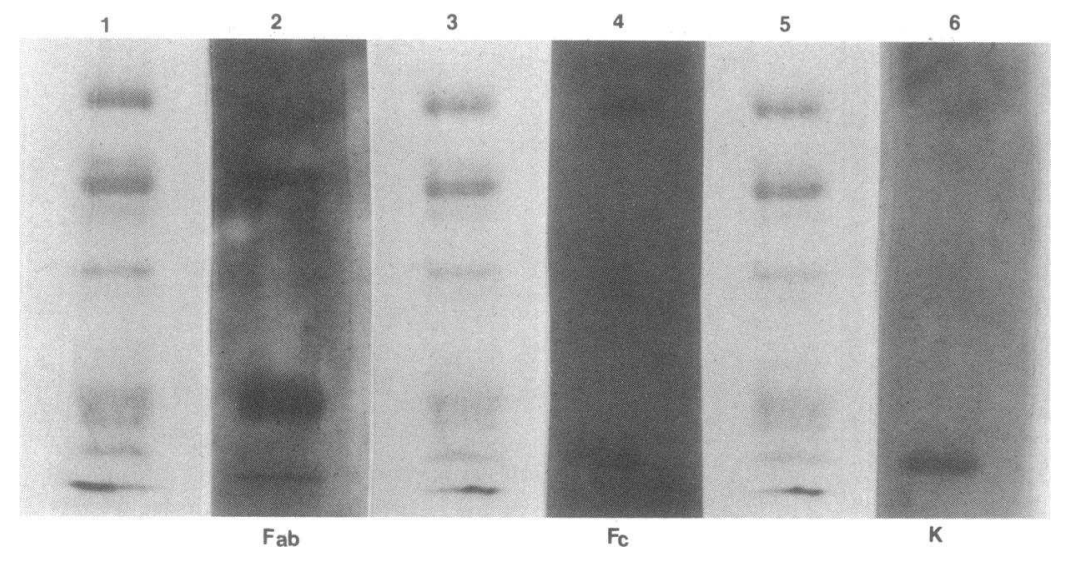

Figure 5. Gel-transfer experiments. SDS-PAG electrophoresis of a single CF lavage fluid IgG fraction was performed in triplicate and the resulting multiple protein bands were stained with Coomassie Brilliant Blue (columns 1, 3, and 5). These protein bands were electrophoretically transferred to nitrocellulose paper; the blots were separated and each identical trans-blot (columns 2, 4, and 6) was counterstained with ${ }^{125} \mathrm{I}$-labeled antisera of differing specificities and developed autoradiographically. The autoradiograph in column 2 was stained with antisera specific for the Fab segment of human IgG, column 4 with anti- $\mathrm{Fc}_{\gamma}$ heavy chain, and column 6 with antisera specific for free $\kappa$ light chains. which the immunoglobulin was largely $158 \mathrm{kD}$ and $7 \mathrm{~S}$ supported somewhat greater bacterial phagocytosis and significantly greater intracellular killing of Pseudomonas (note different scales on upper and lower ordinates). When the 5S fragment of CF respiratory IgG was identified, the handling of Pseudomonas was significantly impaired.

Direct inhibition and immunoglobulin replacement studies. Pepsin and papain proteolysis of IgG antibodies with reactivity to Pseudomonas surface LPS resulted in a variety of peptides with immunoreactivities to $\mathrm{Fc}_{\gamma}$ and $\mathrm{Fab}$. Hydrolytic cleavage of native polyclonal IgG with pepsin largely resulted in the $F\left(a b^{\prime}\right)_{2}$ functional subunit, and papain hydrolysis yielded $F c$ as well as significant amounts of Fab units. Affinity chromatographic techniques employing Staphylococcal protein A made possible clean separation of Fc peptides, the PM surface receptorbinding fragments, from bacterial binding portions of $\mathrm{IgG}$, $\mathrm{F}\left(\mathrm{ab}^{\prime}\right)_{2}$. When increasing concentrations of the $55 \mathrm{kD} \mathrm{Fc}$ and $100 \mathrm{kD} \mathrm{F}\left(\mathrm{ab}^{\prime}\right)_{2}$ subunits were added to the PM-Pseudomonas phagocytic assay system, bacterial uptake was decreased in a stepwise fashion (Fig. 7). $\mathrm{Fc}_{\gamma}$ peptides derived from IgG Pseudomonas antibodies inhibited the uptake of radiotagged $P$. aeruginosa to a greater degree than equimolar amounts of $F\left(a b^{\prime}\right)_{2}$ from the same source.

Native human IgG purified by cold ethanol precipitation and ion-exchange absorption is intact, largely nonaggregated, and suitable for intravenous administration (IVIgG). Such a preparation has significant reciprocal HA titers to all seven Pseudomonas immunotypes: type 1,$32 ; 2,64 ; 3,16 ; 4,256 ; 5$, $8 ; 6,64 ; 7,64$. Likewise, CF patients chronically colonized with Pseudomonas frequently have highest titers to immunotype 4 or 6 when the Fisher immunotyping system is applied (39). After demonstrating in our phagocytic assay that this commercially available IVIgG preparation contained opsonic potential, bacterial uptake and killing curves were simultaneously described over 120-180 min, with and without additional opsonization with IVIgG, using IgG opsonic antibodies derived from the lung lavage fluids obtained from four CF patients (each assayed in duplicate). When intact IgG was added to the opsonic mixture, uptake of Pseudomonas was augmented and intracellular bacterial killing was significantly improved: control, 120 min; mean bacterial uptake $=14.5 \pm 1.1$; after IVIgG, bacterial uptake $=38 \pm 2.1, P<0.05$; control, 120 min mean intracellular killing $=18 \pm 12$; after IVIgG killing $=83 \pm 5, P<0.01$.

By varying the amount of IVIgG used in the opsonization step, holding the amount of a single CF BAL-derived antibody constant, and then quantitating bacterial uptake and killing, the optimal replacement dose of IVIgG was derived which would improve the CF opsonic defect. The experiments summarized in Table IV demonstrate that phagocytosis improves up to a $50 \%$ replacement mixture ([IVIgG (milligrams)/CF BAL IgG (milligrams)] $\times 100 \%)$ and that intracellular killing approaches HIS-facilitated levels up to $100 \%$ mixture. As IVIgG in the opsonic mixture is increased beyond $100 \%$, both phagocytosis and killing fall as a result of clumping of bacteria and immunoglobulins. These data suggest that an $\sim 20 \%$ mixture is optimal because killing does not improve at higher mixtures, and phagocytosis, whereas still inferior to levels attained with HIS, is substantially improved.

\section{Discussion}

It is widely believed that serum and pulmonary immunoglobulins are normal or appropriately increased in those with CF who have chronic airways inflammation characteristic of that disease (40-42). In one of the few published reports to study CF bronchial washings, Zebrak and colleagues quantified six proteins in the lavages of 36 Polish subjects with CF (43). They found that mean IgG, IgA, lactoferrin, and lysozyme levels were elevated. Similar findings have been reported in abstract form by Bell and her colleagues (5). It is also known that CF local humoral responses to a variety of antigens appear intact. Antibodies from CF sputa with specificity for Staphylococcal $\alpha$-hemolysin and Aspergillus have been identified, and Pseudomonas precipitins and agglutinins are very common, having been detected in 33$94 \%$ of sputa (44). Although CF patients show a pronounced antibody response to Pseudomonas in sputum and to a lesser 


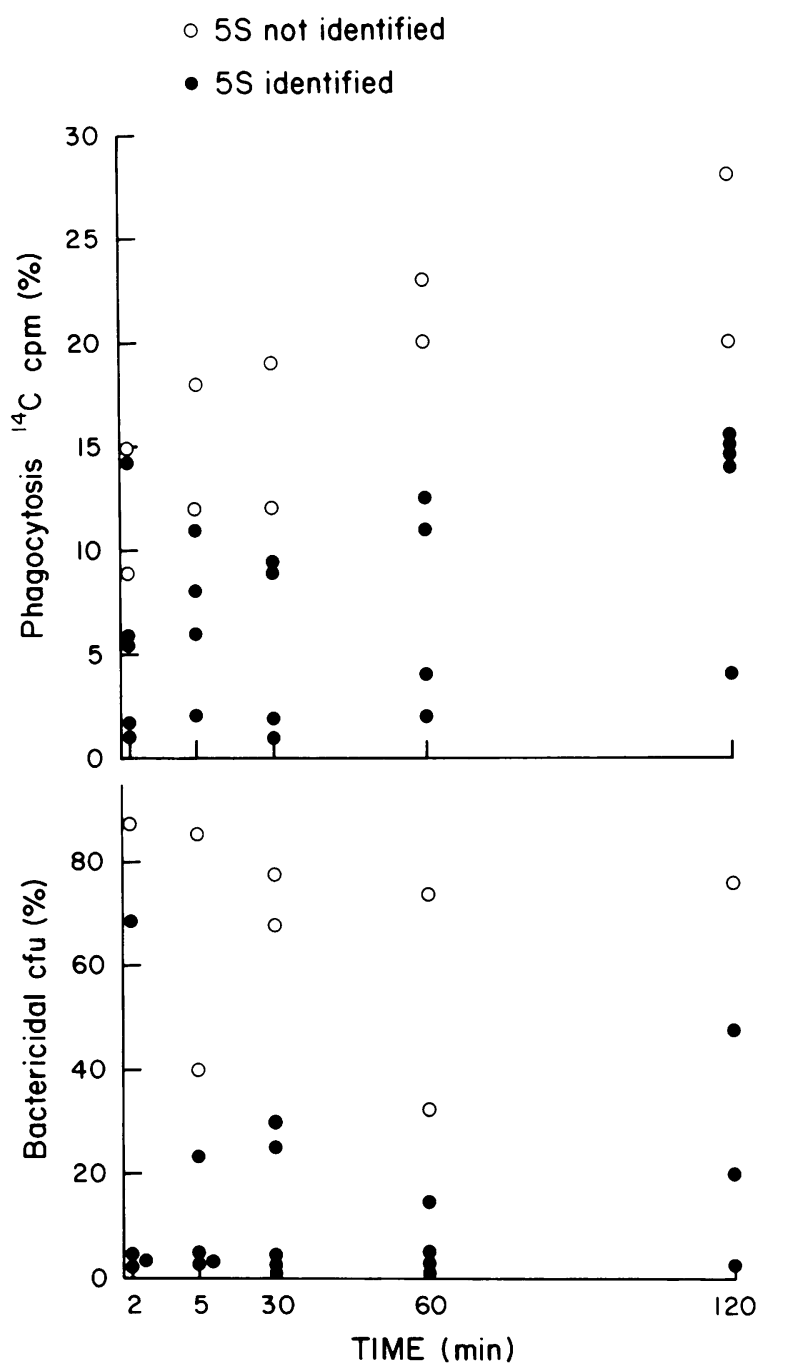

Figure 6. Functional importance of the $5 \mathrm{~S} \mathrm{IgG}$ fragments. Individual data obtained in the phagocytic assay $\left({ }^{14} \mathrm{C} \mathrm{cpm}\right.$, upper ordinate) and the bactericidal assay (CFU, lower ordinate) are plotted at different times after inoculation (minutes, abscissa). Both Pseudomonas uptake and killing were improved when a $5 \mathrm{~S}$ cleavage fragment of IgG was not identified (O). In the CF IgG opsonic preparations derived from respiratory secretions and eluted from a Pseudomonas LPS affinity gel (๑), such a protein fragment was present and phagocytosis of Pseudomonas and killing were depressed.

degree in lung lavage specimens, the functional capacity of these antibodies have not been studied directly.

Despite chronic inflammation of the CF respiratory tract, lavage albumin levels were decreased. This was an unexpected finding, as albumin in BAL is thought to be derived exclusively from the serum by nonspecific transudation (45). A decrease, similar to those reported here, in lavage fluid albumin in patients with chronic lung disease has been reported by others (46). Accordingly, we elected to use total protein as the denominator

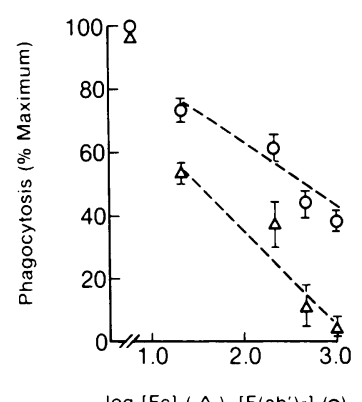

Figure 7. Proteolytic fragments derived in vitro by papain and pepsin hydrolysis of immune IgG, were added to tumbled PM challenged with radiotagged $P$. aeruginos $a$ and a fixed dose $(200 \mu \mathrm{g})$ of intact IgG with Pseudomonas reactivity. Maximal uptake of Pseudomonas by PM was attained in the presence of intact IgG opsonic antibody without $F c$ or $F\left(a b^{\prime}\right)_{2}$ fragments after $60 \mathrm{~min}$ of incubation. Phagocytosis (ordinate), expressed as percent of maximal bacterial uptake, was inversely related $(r>-0.93$ for both) to the concentration (abscissa) of these proteolytic fragments. The concentration of $\mathrm{Fc}$ observed to inhibit phagocytosis to $50 \%$ of maximum was less than that recorded for $F\left(a b^{\prime}\right)_{2}$ fragments; for each $1 \mathrm{log}$ increase in concentration of $\mathrm{Fc}$, phagocytosis decreased $30 \%$; increases in $\mathrm{F}\left(\mathrm{ab}^{\prime}\right)_{2}$ concentrations by $1 \log$ resulted in a $21 \%$ decrease in uptake.

in expressing BAL protein levels (Tables I and II). Such findings might dissuade other investigators from expressing respiratory proteins as a percentage of lavage albumin. Perhaps, like the IgG in CF fluids, albumin may be destroyed by a chronic inflammatory process and hence should not represent the standard against which other protein values are normalized.

The current concept that damage to pulmonary elastic fibers may lead to emphysema and perhaps to bronchiectasis is a potentially important pathogenetic mechanism in the pulmonary disease of CF. The commonly suggested sequence is that destruction occurs because there is an imbalance between proteases and antiproteases, and hence, lung elastases then work unimpeded $(47,48)$. Within the unique milieu of the $C F$ respiratory tract, there are three sources for endogenous elastolytic activity: PMN leukocytes, PM, and Pseudomonas organisms. The strikingly elevated mean level of CF lavage fluid elastase has the inhibitory characteristics of a serine protease, and therefore, may be largely released by the PMN leukocytes that comprise $>80 \%$ of the CF lavage fluid cell differential count. Such protease levels were not matched by significantly increased amounts of the major antielastase of alveolar structures, $\alpha-1-\mathrm{AT}$. Elevated levels of serine proteases such as are found in CF lung fluids complex $\alpha$-1-AT (49), and supernates from P. aeruginosa have also been shown to inactivate this antiprotease (50). Additionally, oxidant damage may inactivate $\alpha-1-\mathrm{AT}$, a possibility suggested

Table IV. IVIgG Optimal Replacement Amounts

\begin{tabular}{llllrrr}
\hline IVIgG (\%)* & 10 & 20 & 50 & 100 & 1000 & 2000 \\
Mean phagocytosis (\%) $¥$ & 32 & 56 & 68 & 63 & 61 & 19 \\
Mean killing (\%) & 63 & 93 & 92 & 93 & 88 & 53
\end{tabular}

* Expressed as (IVIgG [mg]/CF anti-Pseudomonas immunotype 4 IgG [mg]) $\times 100 \%$.

‡ PM monolayer assayed after $90 \mathrm{~min}$ 
by the presence of excess numbers of PMN leukocytes. Clearly, the number of samples we studied was small, and antigenic, not functional $\alpha$-1-AT levels were assessed. Nevertheless, lung degradation by both direct and indirect elastinolysis remains a potential pathogenetic mechanism for CF lung disease and is an area that warrants additional investigation.

In this report, data from a variety of assays suggest that the Pseudomonas-reactive IgG opsonins are fragmented in the lavage fluids of patients with CF. Initially, during stages of isolating IgG from these fluids, double immunodiffusion analyses showing concentric immunoprecipitin arcs suggested that IgG fragments were present. Such fragments would have a different mobility in agar but could still contain some of the antigenic determinants of intact IgG $\left(\mathrm{Fab}, \mathrm{Fc}_{\gamma}\right)$. SDS-PAG molecular weight determinations showed that total CF lavage fluid IgG contained multiple protein bands with molecular weights between 24,000 D and 158,000 D. The affinity-purified LPS Type 4 preparation of IgG antibody in five of our seven lavages studied in this fashion contained a single fragment in addition to smaller amounts of intact Pseudomonas reactive IgG. This fragment resembled the $F\left(a b^{\prime}\right)_{2}$ fragment with a molecular weight of $100,000 \mathrm{D}$ and a sedimentation coefficient of 5S. Gel transfer and autoradiographic experiments demonstrated Fab antigenic reactivity to be present in this cleavage product. High levels of IgG such as are present in CF BAL samples, when determined by the Mancini technique of radial-immunodiffusion, are compatible with IgG fragmentation, as artificially elevated levels may be produced by smaller cleavage fragments containing antigenic reactivity but with an improved diffusability in agar gel.

Although occasional reports have described hypogammaglobulinemia-G in up to $20 \%$ of younger patients with CF (51), numerous studies have reported normal or elevated serum and lung lavage immunoglobulin levels. Other than a recent abstract (52), there are no previous descriptions of fragmentation of $\mathrm{IgG}$ in this disease. IgA and secretory-IgA, however, have been examined and a variety of cleavage fragments have been described. Wallwork and McFarlane described CF patients with a high proportion of serum specimens containing free secretory pieces (SC), increased amounts of J-chain, and alteration of SC in CF sputum samples (53). Additionally, purified CF SC differed in electrophoretic mobility from normal salivary SC. These authors suggested a defect in the synthesis of IgA existed in this disease. The postulate that IgA-secretory IgA are cleaved within the CF respiratory tract is equally possible.

As predicted from our immunochemical analyses, CF respiratory IgG antibodies are poor opsonins for $P$. aeruginosa. Despite significant hemagglutinating activity, these CF antibodies resulted in a bacterial phagocytic rate that did not differ from the IgG control in which no Pseudomonas-agglutinating activity was present. Normal human alveolar macrophages are potent bactericidal phagocytes when properly primed by effective IgG opsonins. When Pseudomonas-reactive IgG opsonins were derived from the sera of vaccine-immunized volunteers, $>89 \%$ of the bacteria taken up were no longer viable; the process of engulfment is closely linked to intracellular killing mechanisms. CF IgG antibodies appear to uncouple these processes. This concept is suggested by the results presented in Table III which show numbers of viable bacteria increasing to $60 \mathrm{~min}$ when $\mathrm{CF}$ or nonimmune normal volunteer sera serve as sources for IgG antibodies. Such is not the case for HIS and chronic obstructive pulmonary disease IgG opsonins.

In previous work, we described similar defects in opsoninmediated alveolar macrophage phagocytosis and killing of Pseudomonas when the IgG antibodies were derived from CF sera (7). In those studies with peripheral IgG antibody, intracellular killing was mildly impaired compared with the positive control: $89 \%$ of Pseudomonads internalized by PM were killed after 120 min. This defect is more marked in the current work as only $54-70 \%$ of internalized bacteria are killed after $120 \mathrm{~min}$. No doubt such findings relate to the degree of cleavage of IgG antibodies and the amount of free Fc fragments present in the two pools. If the site of proteolysis is within the CF respiratory tract, as we have speculated, proteolytic products would be expected to be present there in greater concentrations. The immunoglobulin fragments present in the peripheral circulating pool may represent only small amounts released from the site of generation. Sensitive functional assays such as we employed (7) suggested the presence of defective $\mathrm{Fc}_{\gamma}$ segments there as well.

The presence of free $F\left(a b^{\prime}\right)_{2}$ segments in our affinity-purified preparations correlated in an inverse fashion with phagocytic and bacterial functions of those antibodies. Reconstitution experiments (Table IV) with intact IgG to compete for binding to both bacterial and macrophage surfaces seemed successful. Increasing the percentage of intact replacement IgG, relative to amounts of CF IgG present in the opsonic mixture, to $\sim 20 \%$ resulted in significantly improved bacterial uptake and normal rates of killing.

The proteolysis of IgG Pseudomonas antibodies is a potentially important finding. Opsonizing antibodies, in particular LPS-type specific of the IgG class, together with alveolar macrophages equipped with $\mathrm{Fc}_{\gamma}$ receptors provide a major defense mechanism against Pseudomonas in the respiratory tract (54, 55). Because of the importance of immune IgG in the phagocytic process and special constraints in antibody binding to macrophages imposed by specific cell surface receptors (11), alteration of respiratory IgG is of some importance to the understanding of CF lung disease. Fragmented immune IgG cannot serve as an effective opsonin without the $\mathrm{Fc}_{\gamma}$ portion which is necessary to bind to PM surface receptors, trigger internalization, and perhaps, mediate intracellular killing of bacteria. Such functions are not associated with the Fab antigen-binding activity. Furthermore, as our studies with proteolytically derived Fc and $\mathrm{F}\left(\mathrm{ab}^{\prime}\right)_{2}$ fragments demonstrate, these cleavage products inhibit the uptake of Pseudomonas by PM. Papain-derived Fc fragments, by binding to phagocyte surface receptors more effectively, interferred with the phagocytic process. It is possible that the immune $F\left(a b^{\prime}\right)_{2}$ generated with pepsin hydrolysis in some cases 
retained sufficient $\mathrm{C}_{\gamma} 2$ active sites permitting continued macrophage surface receptor attachment. Thus, the Fc moieties could be, in effect, serving as the bactericidal blocking antibodies that Hoiby has postulated to exist in CF (4), and free $F\left(a b^{\prime}\right)_{2}$ with Pseudomonas reactivity may to a lesser degree be the blocking factor described by Guttman and Waisbren in those with chronic Pseudomonas infections (56). It is likely that proteolytic enzymes within CF airways cleave Pseudomonas opsonins into effete fragments. Sources for such enzymes include PMN leukocytes, macrophages, and Pseudomonas bacteria themselves. Animal and human PM are known to contain a variety of neutral hydrolases, such as collagenase, elastase, and phospholipases (57), and certain bacteria can produce an IgA, protease (58).

Commercially prepared enzyme-digested IgG preparations are suitable only for intramuscular administration and the dose that can be administered is limited. As is the case with CF respiratory IgG opsonins, those commercial preparations lack the Fc region of IgG and for this reason, have suboptimal opsonizing activity. In contrast, use of the cold ethanol extraction method results in IgG antibodies of which $94 \%$ are monomeric and all of the opsonizing and antigen-binding properties are intact (59). With such preparations, intravenous administration is possible and larger amounts may be given more frequently. If defects such as we have described in CF opsonins are confirmed by others, it might be reasonable to consider cautious administration of replacement therapy in the proper clinical situation. Both the magnitude of human suffering and the economic costs to our society of this disease should catalyze such confirmatory experiments and clinical trials.

\section{Acknowledgments}

The authors wish to acknowledge the technical assistance of Ms. Lydia Polomski and Lori Fritts. We thank Mr. Emanuel Lerner for his help with the SAS and Datatext computer programs, and acknowledge the excellent secretarial assistance of Mrs. Mae Day, Ms. Mary Uhl, and Mrs. Deanna Ollendick. Suggestions by Dr. Gary W. Hunninghake and Dr. William Nauseef were helpful during the completion of this work.

This work was supported by grants HL-19237 (Dr. Gee) and HL22302 (Dr. Reynolds).

\section{References}

1. Thomassen, M. J., C. A. Demko, R. E. Wood, B. Tandler, D. G. Dearborn, B. Boxerbaum, and P. J. Kuchenbrod. 1980. Ultrastructure and function of alveolar macrophages from cystic fibrosis patients. $P e-$ diatr. Res. 14:715-721.

2. Boxerbaum, B., H. Kagumba, and L. W. Matthews. 1973. Selective inhibition of phagocytic activity of rabbit alveolar macrophages by cystic fibrosis serum. Am. Rev. Respir. Dis. 108:777-783.

3. Biggar, W. D., B. Holmes, and R. A. Good. 1971. Opsonic defect in patients with cystic fibrosis of the pancreas. Proc. Natl. Acad. Sci. USA. 68:1716-1719.

4. Hoiby, N., and S. Olling. 1977. Pseudomonas aeruginosa infection in cystic fibrosis. Bactericidal effect of serum from normal individuals and patients with cystic fibrosis on $P$. aeruginosa strains from patients with cystic fibrosis or other diseases. Acta Pathol. Microbiol. Scand. 85(3):107-114.
5. Bell, D., and A. Spock. 1980. Immunoglobulins of the distal airways of the lung in cystic fibrosis. In Perspectives in Cystic Fibrosis. J. M. Sturgess, editor. Canadian Cystic Fibrosis Foundation, Toronto, Canada. 3A.

6. Fick, R. B., G. P. Naegel, and H. Y. Reynolds. 1980. Use of Pseudomonas aeruginosa lipopolysaccharide and immunoadsorbents to prepare high potency, monospecific antibodies. J. Immunol. Methods. 38:103-116.

7. Fick, R. B., G. P. Naegel, R. A. Matthay, and H. Y. Reynolds. 1981. Cystic fibrosis Pseudomonas opsonins. Inhibitory nature in an in vitro phagocytic assay. J. Clin. Invest. 68:899-914.

8. Reynolds, H. Y., and R. E. Thompson. 1973. Pulmonary host defenses. II. Interaction of respiratory antibodies with Pseudomonas aeruginosa and alveolar macrophages. J. Immunol. 111:369-380.

9. Young, L. S., and D. Armstrong. 1972. Human immunity to Pseudomonas aeruginosa. I. In vitro interaction of bacteria, polymorphonuclear leukocytes, and serum factors. J. Infect. Dis. 126:257-276.

10. Reynolds, H. Y., J. A. Kazmierowski, and H. H. Newball. 1975. Specificity of opsonic antibodies to enhance phagocytosis of Pseudomonas aeruginosa by human alveolar macrophages. J. Clin. Invest. 56:376385.

11. Reynolds, H. Y., J. P. Atkinson, H. H. Newball, and M. M. Frank. 1975. Receptors of immunoglobulin and complement on human alveolar macrophages. J. Immunol. 114:1813-1819.

12. Quie, P. G., R. P. Messner, and R. C. Williams, Jr. 1968. Phagocytosis in subacute bacterial endocarditis. Localization of the primary opsonic site to Fc fragment. J. Exp. Med. 128:553-570.

13. Abramson, N., E. W. Gelfand, and J. H. Jandl. 1970. The interaction between human monocytes and red cells: specificity for IgG subclasses and IgG fragments. J. Exp. Med. 132:1207-1215.

14. Reynolds, H. Y., and R. B. Fick. 1980. Pseudomonas aeruginosa pulmonary infections (emphasizing nosocomial pneumonia and respiratory infections in cystic fibrosis). In Pseudomonas aeruginosa, the Organism, Diseases It Causes and Their Treatment. L. D. Sabath, editor. Hans Huber Publisher, Bern, Switzerland. 71-88.

15. Pennington, J. E., H. Y. Reynolds, R. E. Wood, R. A. Robinson, and A. S. Levine. 1975. Use of Pseudomonas aeruginosa vaccine in patients with acute leukemia and cystic fibrosis. Am. J. Med. 58:629636.

16. Reynolds, H. Y., and H. H. Newball. 1974. Analysis of proteins and respiratory cells obtained from human lungs by bronchial lavage. J. Lab. Clin. Med. 84:559-573.

17. Merrill, W. W., G. P. Naegel, R. A. Matthay, and H. Y. Reynolds. 1980. Alveolar macrophage-derived chemotactic factor: kinetics of in vitro production and partial characterization. J. Clin. Invest. 65:268276.

18. Lowry, O. H., N. J. Rosebrough, A. L. Farr, and R. Randall. 1951. Protein measurement with the folin phenol reagent. Biol. Chem. 193:265-269.

19. Higerd, T. B., F. Birella, R. Cardenas, J. Koistiner, and J. W. Fett. 1977. New method for obtaining IgA specific protease. J. Immunol. Methods. 18:245-249.

20. Hinman, L. M., C. A. Stevens, R. A. Matthay, and J. B. L. Gee. 1980. Elastase and lysozyme activities in human alveolar macrophages. Am. Rev. Respir. Dis. 121:263-271.

21. Bielefeld, D. R., R. M. Senior, and S. Y. Yu. 1975. A new method for determination of elastolytic activity using $\left[{ }^{14} \mathrm{C}\right]$ labeled elastin and its application to leukocytic elastase. Biochem. Biophys. Res. Commun. 67:1553-1559. 
22. Bieth, J., and C. G. Wermuth. 1973. Action of elastases on paranitroanilide substrates. Biochem. Biophys. Res. Commun. 53:383-390.

23. Baugh, R. M. J., and J. Travis. 1976. Human leukocyte granule elastase: rapid isolation and characterization. Biochemistry. 15:836-841.

24. Banda, M. J., and Z. Werb. 1981. Mouse macrophage elastase: purification and characterization as a metalloproteinase. Biochem. $J$. 589:685-687.

25. Mandl, I., S. Keller, and B. Cohen. 1962. Microbial elastases. A comparative study. Proc. Soc. Exp. Biol. Med. 109:923-925.

26. Reynolds, H. Y., and J. S. Johnson. 1971. Structural units of canine serum and secretory immunoglobulin A. Biochemistry. 10:28212827.

27. Porter, R. R. 1959. The hydrolysis of rabbit $\gamma$-globulin and antibodies with crystalline papain. Biochem. J. 73:119-123.

28. Nisonoff, A., G. Markus, and F. Wissler. 1961. Separation of univalent fragments of rabbit antibody by reduction of a single, labile disulphide bond. Nature (Lond.). 189:293-297.

29. Goding, J. W. 1978. Use of Staphylococcal Protein A as an immunological reagent. J. Immunol. Methods. 20:241-253.

30. Murphey, S. A., R. K. Root, and A. D. Schreiber. 1979. The role of antibody and complement in phagocytosis by rabbit alveolar macrophages. J. Infect. Dis. 140:896-903.

31. Maurer, P. H. 1971. Precipitation reactions. Methods Immunol. Immunochem. 3:1-58.

32. Wieme, R. J. 1959. An improved technique of agar-gel electrophoresis on microscope slides. Clin. Chim. Acta. 4:317-321.

33. Fraker, P. J., and J. C. Speck. 1978. Protein and cell membrane iodinations with a sparingly soluble chloramide, 1,3,4,6-tetrachloro-3a,6adiphenyl glycoluril. Biochem. Biophys. Res. Commun. 80:849-857.

34. Laemmli, U. K. 1970. Cleavage of structural proteins during the assembly of the head of bacteriophage T4. Nature (Lond.). 227:680685 .

35. Stephens, R. E. 1975. High resolution preparative SDS-polyacrylamide gel electrophoresis: fluorescent visualization and electrophoretic elution-concentration of protein bands. Anal. Biochem. 65:369379.

36. Weber, K., and M. Osborn. 1969. The reliability of molecular weight determinations by dodecyl sulfate polyacrylamide gel electrophoresis. J. Biol. Chem. 244:4406-4412.

37. Towbin, H., T. Staehelin, and J. Gordon. 1979. Electrophoretic transfer of proteins from polyacrylamide gels to nitrocellulose sheets: procedure and some applications. Proc. Natl. Acad. Sci. USA. 76:43504354.

38. Fick, R. B., and H. Y. Reynolds. 1983. Pseudomonas respiratory infection in cystic fibrosis: a possible defect in opsonic IgG antibody? Bull. Eur. Physiopathol. Respir. 19:151-161.

39. Zierdt, C. H., and R. L. Williams. 1975. Serotyping of Pseudomonas aeruginosa isolates from patients with cystic fibrosis of the pancrease. J. Clin. Microbiol. 1:521-526.

40. Martinez-Tello, F. J., D. G. Brown, and W. A. Blanc. 1968. Immunoglobulin production in bronchial mucosa and bronchial lymph nodes, particularly in cystic fibrosis of the pancreas. J. Immunol. 101:9891003.

41. Talamo, R. C., E. R. Stiehm, and R. H. Schwartz. 1976. Immunologic aspects of cystic fibrosis. In Cystic Fibrosis Projections Into the Future. J. A. Mangos and R. C. Talamo, editors. Stratton Intercontinental Medical Book Corporation, New York. 195-217.

42. Wood, R. E., T. F. Boat, and C. F. Doershuk. 1976. State of the art: cystic fibrosis. Am. Rev. Respir. Dis. 113:833-878.
43. Zebrak, J., T. Herman, R. Werys, J. Pryjma, and J. Gawel. 1979. Proteins in bronchial secretion of children with chronic pulmonary diseases. II. Relation to bronchoscopic and bronchographic examination. Scand. J. Respir. Dis. 60:69-75.

44. Fick, R. B., and H. Y. Reynolds. 1980. Immunoprophylaxis and immune responses in cystic fibrosis. In Perspectives in Cystic Fibrosis. J. M. Sturgess, editor. Canadian Cystic Fibrosis Foundation, Toronto, Canada. 335-345.

45. Low, R. B., G. S. Davis, and M. S. Giancola. 1978. Biochemical analysis of bronchoalveolar lavage fluids of normal healthy volunteers. Am. Rev. Respir. Dis. 118:863-876.

46. Bell, D. Y., A. Spock, and G. E. R. Hook. 1980. Plasma proteins of the bronchoalveolar lining of the lung in cystic fibrosis. Proc. Cystic Fibrosis Club. 21:33.

47. Kuhn, C., and R. M. Senior. 1978. The role of elastases in the development of emphysema. Lung. 155:185-197.

48. Gadek, J. E., G. A. Fells, R. L. Zimmerman, S. I. Rennard, and R. G. Crystal. 1981. Antielastases of the human alveolar structures. Implications for the protease-antiprotease theory of emphysema. J. Clin. Invest. 68:889-898.

49. Starke, P. M. 1971. Elastase and cathepsin G; a serine protease of human leukocytes. In Proteases in Mammalian Cells and Tissues. A. J. Barrett, editor. North-Holland Publishing Co., New York. 57-87.

50. Moskowitz, R. W., and G. Heinrich. 1971. Bacterial inactivation of human serum alpha-1-antitrypsin. J. Lab. Clin. Med. 77:777-785.

51. Matthews, W. J., M. Williams, B. Oliphint, R. Geha, and H. R. Colton. 1980. Hypogammaglobulinemia in patients with cystic fibrosis. N. Engl. J. Med. 302:245-249.

52. Bell, D. Y., and A. Spock. 1982. Immunoglobulin G fragments with lavage fluids from the lungs of patients with cystic fibrosis. Am. Rev. Respir. Dis. 125:201. (Abstr.)

53. Wallwork, J. C., and H. McFarlane. 1976. The SIgA system and hypersensitivity in patients with cystic fibrosis. Clin. Allergy. 6:349-358.

54. Reynolds, H. Y., and R. E. Thompson. 1973. Pulmonary host defenses. II. Interaction of respiratory antibodies with Pseudomonas aeruginosa and alveolar macrophages. J. Immunol. 111:369-380.

55. Bjornson, A. B., and J. G. Michael. 1971. Contribution of humoral and alveolar factors to the resistance to experimental infection by Pseudomonas aeruginosa in man. I. Interaction between immunoglobulins, heat-labile serum factors, and phagocytic cells on the killing of bacteria. Infect. Immun. 4:462-467.

56. Guttman, R. M., and B. A. Waisbren. 1975. Bacterial blocking activity of specific IgG in chronic Pseudomonas aeruginosa infection. Clin. Exp. Immunol. 19:121-130.

57. Gee, J. B. L., and R. B. Fick. 1981. Alveolar macrophage and nonrespiratory functions of the lung. In Pathophysiology of the Reticuloendothelial System. B. M. Altura and T. M. Saba, editors. Raven Press, New York. 47-91.

58. Kilian, M., J. Mestecky, R. Kulhavey, M. Tomana, and W. T. Butler. 1980. IgA, Proteases from Hemophilus influenzae, Streptococcus pneumoniae, Neisseria meningitidis, and Streptococcus sanguis: comparative immunochemical studies. J. Immunol. 124:2596-2600.

59. Sadoff, J. C., H. Sidberry, J. Schilhab, D. Hirschfeld, and A. Cross. 1980. Opsonic and bacterial-binding activity of immunoglobulin preparations. In Immunoglobulin: Characteristics and Uses of Intravenous Preparations. B. Alving and J. S. Finlayson, editors. No. (FDA) 80-9005, United States Government Printing Office, Washington, DC. 63-71. 